\title{
Empirical Study on the Effectiveness of Technology Application towards Students' Good Feedback Practice
}

\author{
Nurul Nisa Omar* \\ KDU University College, Glenmarie, Selangor, Malaysia. \\ * Corresponding author. Tel.: +6 017317 0442; email: nurulnisa.o@kdu.edu.my \\ Manuscript submitted May 10, 2017; accepted September 23, $2017 .$. \\ doi: 10.17706/ijeeee.2018.8.2.173-180
}

\begin{abstract}
Technology application in a classroom is widely used in assisting educators to perform more engaging and captivating activities with students. More recently, however, there are several concerns towards students' performance level and the quality of feedback gained from the usage of technology application approach in classroom assessment. In this article, the author will discuss the effectiveness of technology application as an assessment tool in classroom activities by studying the usage of Kahoot assessment tool. Results from this study will showcase a comparison study on students' performance level in classroom assessment with and without technology application method. The contribution will deepen the understanding of the implication of technology application in assessment activities towards students' good feedback practice.
\end{abstract}

Key words: Good feedback practice, learning technology, Kahoot assessment.

\section{Introduction}

Technology application in classroom has proven to bring many good benefits as a teaching and learning tool [1]. Particularly in media studies, it is difficult to imagine teaching courses without having educators applying some form of technology to engage learners with class activities. A research [2] explicitly expresses how educators are highly encouraged to appropriately and effectively use technology related approach in managing their classroom lesson. However, past study [3] expresses that there are many issues in regards to the success of using technology in class. One of the related concern would be the effectiveness of technology in classroom assessment towards students' feedback practices [4].

In terms of technology application for in-class assessment, the concept is to have students receiving instructions, answering questions and assessing feedback without the teacher being present [5], [6]. The whole idea is to make learning become more dynamic, open ended and multidimensional. Digital technology usage in classroom assessment are able to mimic the typical traditional evaluation practices such as; multiple choice questions, short answers and true or false responses to name a few [7]. Many current higher education have begun to practice the usage of technology-based assessment and feedback as part of in-class activities [8].

A study [9] discusses the seven principles of good feedback practices in improving students' performance and accelerate learning. These seven principles can also be used in assessing the effectiveness of technology assessment approach in class. The identified seven principles as are follows:

1) Helps clarify what good performance is (goals, criteria, expected standards) 
2) Facilitates the development of reflection and self-assessment in learning

3) Delivers high quality information to students about their learning

4) Encourages teacher and peer dialogue around learning

5) Encourages positive motivational beliefs and self-esteem

6) Provides opportunities to close the gap between current and desired performance

7) Provides information to teachers that can be used to help shape the teaching

The mentioned principles refers to technology-supported assessments that are fully online or anything that involves online-offline interactions [9]. To incorporate technology fully into classroom will require severe changes in the education system itself. A study [10] discusses how the changes are not only for educators but also for administrators, experts, institutions directors and many others. Thus for a start, educators are first exposed with many different types of educational technology application such as Kahoot. Kahoot from the website getkahoot.com; is a platform for educators and learners to create, play and share fun learning assessment for any subject. It is interactive and engaging with features includes in-class activities such as quiz, discussion, and survey. The usage of Kahoot in the classroom is able to create extra excitement to boost up learners' attitude and participation in class. Additionally, the interface is also very easy to use with clearly written instruction. However, there are no certainty that the implementation of Kahoot in classroom assessment can encourage good feedback practice in accelerating students' performance.

\section{Research Objectives}

Higher education institutions keeps on investing in technology application for a more systematic and relevant educational approach [11]. Thus it is important to study whether or not this technology can actually improve students' performances in class. This research will investigate the effectiveness of technology application, specifically on Kahoot application as an assessment tool in classroom activities. The underlying factor is to assess whether or not having to sit for a test in classroom via technology application will accelerate students' performance in comparison to traditional way of writing answers by using pen and paper. Therefore, this research will answer the following research questions:

1) Does the usage of Kahoot assessment method improve students' performances in class?

2) What type of feedback practices are involved from the usage of Kahoot assessment method in class?

\section{Methodology}

This study employs quantitative questionnaires on selected students in a classroom setting. As a case study, 150 students from media and communication course were chosen to take part in the questionnaires. The empirical research study will be done in two phases by conducting two different types of assessment method. The assessment will be done on two different topics of one media subject but with the same level of difficulties for both topics.

Phase 1: The first phase were conducted at the end of the first lesson plan. Students will be given a traditional test assessment where they will need to assess their knowledge about the topic. Students' performances were recorded and at the end of the test, they were given sets of questionnaires their performance were recorded for the comparison study.

Phase 2: The second phase were conducted at the end of the second lesson plan, but covering the same knowledge level as the first lesson plan. In comparison to the first phase, students will go through the assessment by using technology application method called Kahoot. At the end of the assessment, students' performances will be recorded and they will answer sets of questionnaires to assess the good feedback practices that they experienced from technology-based assessment method. The questionnaires were 
crafted based on the seven identified principles of good feedback practice by [9]. These two phases of data collection method will provide a comparison in terms of students' performance level and perception.

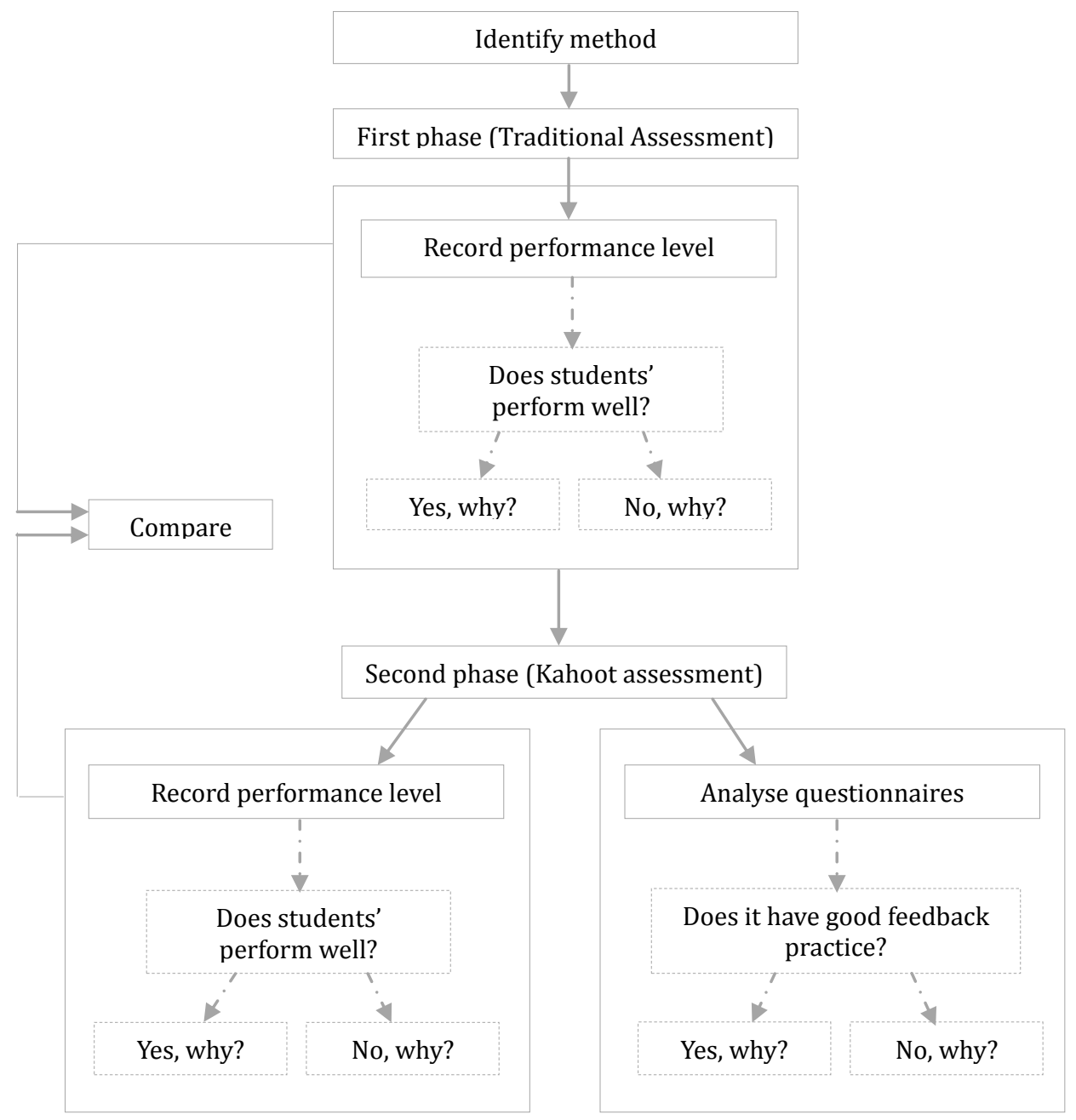

Fig. 1. Phases of research methods.

As presented in Fig. 1, comparison study were done towards respondents' performance level and perception towards traditional assessment method against technology application. Additionally, this is to investigate the effect of technology application in classroom towards students' performances and good feedback practices among students and lecturers.

\section{Findings and Discussions}

Following the data collection process, students' performances were recorded based on the percentage of outstanding, passing and failing grade from both traditional and technology application (Kahoot) assessments. Outstanding grades consists of students who manage to score $80 \%$ and above, passing grades consists of students who manage to score $50 \%$ and above, failing grade consist of students who scored $49 \%$ and below. Additionally, students were asked to conduct a self-evaluation towards their performance level after sitting for both test. Students' feedback were tabulated according to the summary of responses and the frequency value of the responses.

Table 1 showcases students' assessment scores from two different types of assessments. Looking at traditional assessment, $20 \%$ out of total of 150 students manage to achieve outstanding score in comparison with only $15 \%$ outstanding scores from Kahoot assessment. Even though the number of 
students who scored outstanding from traditional assessment is higher in comparison to Kahoot assessment, the differences were merely a small percentage of $5 \%$. In regards to the passing grade, Kahoot assessment produce higher number of $81 \%$ in comparison with only $75 \%$ passing grade from traditional assessment.

Table 1. Students' Assessment Scores

\begin{tabular}{lcc} 
Scores & Traditional Assessment & Kahoot Assessment \\
\hline Outstanding & $20 \%$ & $15 \%$ \\
Pass & $75 \%$ & $81 \%$ \\
Fail & $5 \%$ & $3 \%$ \\
\hline $\mathrm{N}=150$ & &
\end{tabular}

Even though it is not a huge different, it is still a significance increment of $6 \%$ of passing grade by using Kahoot assessment method. Looking at the failing grade, traditional assessment produces higher failing grade in comparison to Kahoot assessment with 5\% over 3\%. Findings from Table 1 explicitly showcase that students' performance level have a slight improvement following higher passing rate generated from Kahoot assessment in comparison to traditional assessment.

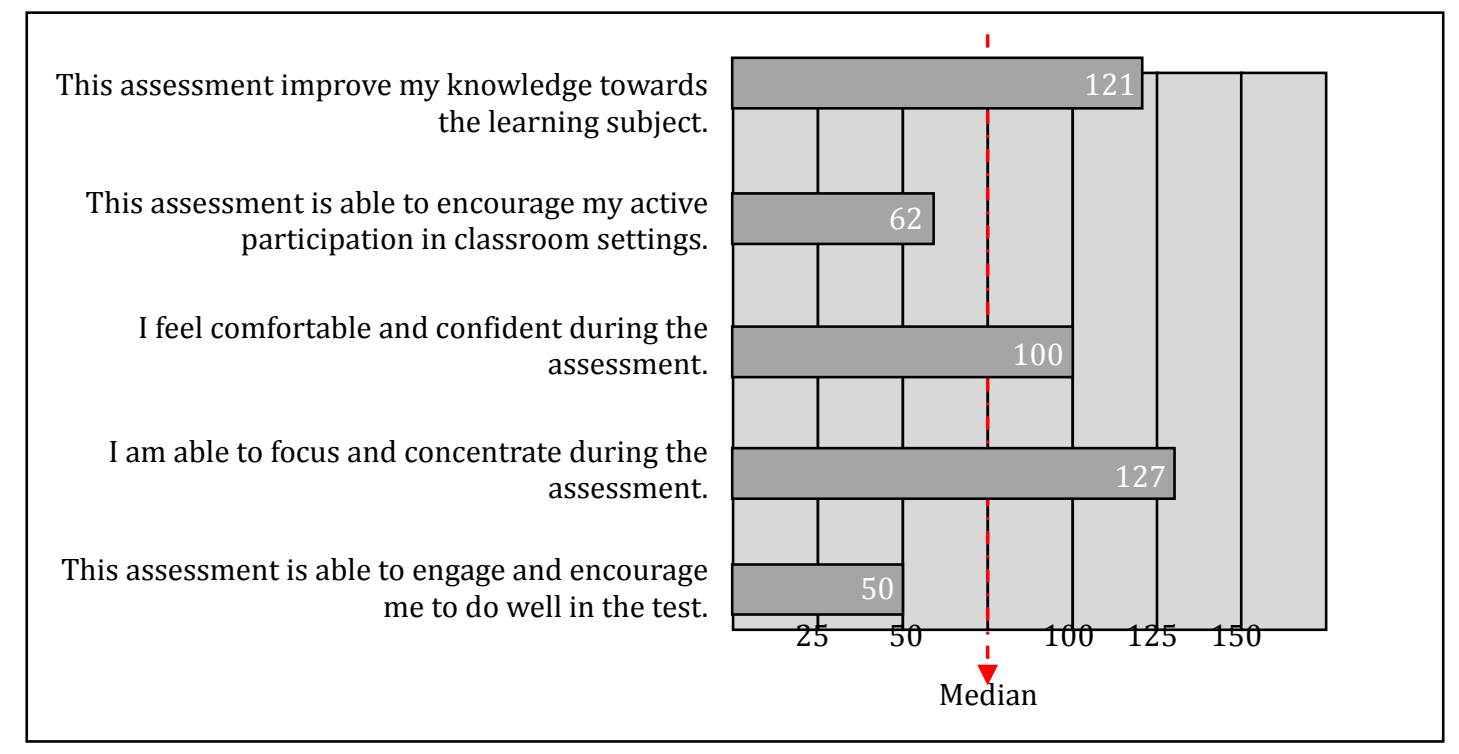

Fig. 2. Summary of responses on students' self-evaluation towards traditional assessment.

Fig. 2 showcases students' self-evaluation towards traditional assessment. From the summary of responses, lesser respondents at only 62 stated that traditional assessment can encourage students' participation in classroom and 50 stated that it is engaging and encouraging for students to perform well in the test.

This showcase that majority of students did not feel encouraged and motivated to participate in traditional assessment. However, big marginal of respondents at 121 stated that traditional assessment can improve their knowledge towards the subject and 127 stated that they are able to focus and concentrate in the test. Additionally, 100 respondents feel comfortable and confident with traditional assessment. 
Fig. 3 showcases students' self-evaluation towards Kahoot assessment. From the summary of responses, lesser respondents at only 65 stated that Kahoot assessment is able to make students more focus and concentrate during the assessment. This showcase that majority of students are not able to concentrate well during the test. However, big marginal of respondents at 121 stated that traditional assessment can improve their knowledge towards the subject, 132 stated that they are encouraged and very active in participating with the assessment, 122 stated that they are more engaged and motivated to perform well in the assessment. Additionally, 102 respondents stated that they are comfortable and confident while sitting for the test.

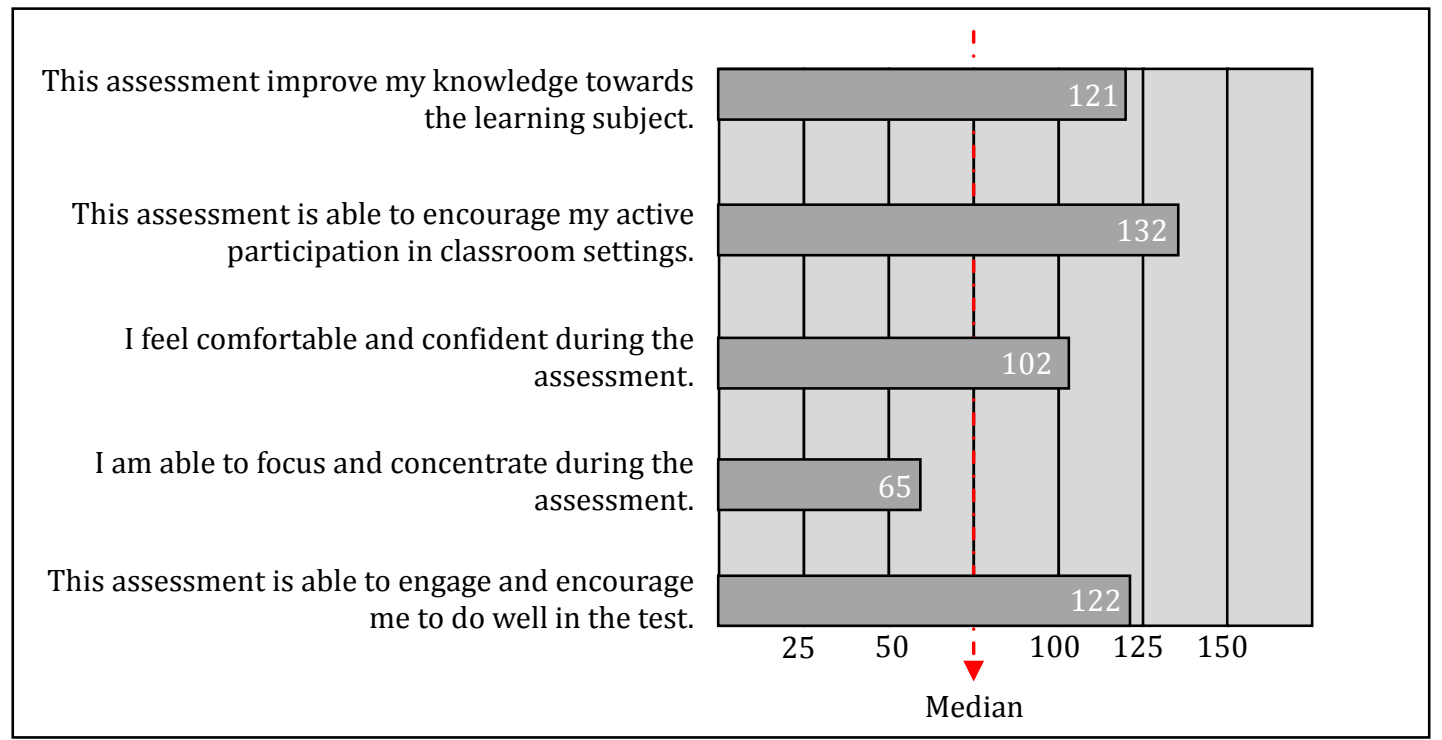

Fig. 3. Summary of responses on students' self-evaluation towards Kahoot assessment

Respondents deemed to be able to improve their knowledge towards the subject and very comfortable and confident with both traditional and Kahoot assessment. The advantage of traditional assessment in comparison to Kahoot assessment is that students are able to focus and concentrate more during the test. Previous study [10] discusses that changes are necessary in making students and educators adapt to the concept of technology application in classroom assessment and with Kahoot, the assessment is done by having the results and questions projected on screen where it can be a distraction for students' concentration and focus. Nevertheless, Kahoot assessment is able to encourage students' active participation and motivation to perform well in the test in comparison to traditional assessment. Technology application assessment is an activity where it involves a lot of interaction [9] which makes it more dynamic and multidimensional [6]. In Kahoot, respondents' scores were displayed for everyone to see and solving a question must be within a given timeframe per question. Hence it encourage students to be more active in looking for answer before time is up in order to achieve more points than others. As Table 1 presented that students' passing rate in higher from Kahoot assessment in comparison to traditional assessment, it is because Kahoot assessment is more engaging and encouraging in comparison to traditional assessment as presented in Fig. 2 and Fig. 3.

Knowing that Kahoot assessment can improve students' performance level, it is vital to know what types of feedback practices does students' experience during the assessment. The seven principles of good feedback practice includes clarification of learners' goal, facilitation in self-assessment, delivers high quality information, encourages educators and learners to discuss, encourage self-esteem, provide opportunities to achieve desired performance and assist educators with teaching duty [9]. 
I am aware of what I need to achieve in order to do well in this test.

The expected standard in meeting the criteria of the test is clearly delivered.

I can assess my own performance against others' performance after I have completed the test.

This assessment encourage me to reflect upon my results and performance.

After sitting for the test, I understand a lot more information about the subject.

The test provide me with good knowledge on my learning capabilities.

I am able to discuss and have conversation with my lecturer in regards to the assessment.

The test give me more opportunities to converse any issues in regards to the subject content.

This assessment boost my self-esteem towards my performance in class.

This type of test makes me feel more motivated to participate in class activities.

I am able to achieve my desired scores with the help of this assessment.

This test can help me to perform well for the subject.

This assessment manage to assist the lecturer to run a good practice during class activities.

The lecturer's teaching skills improves by using this type of approach in assessing students.

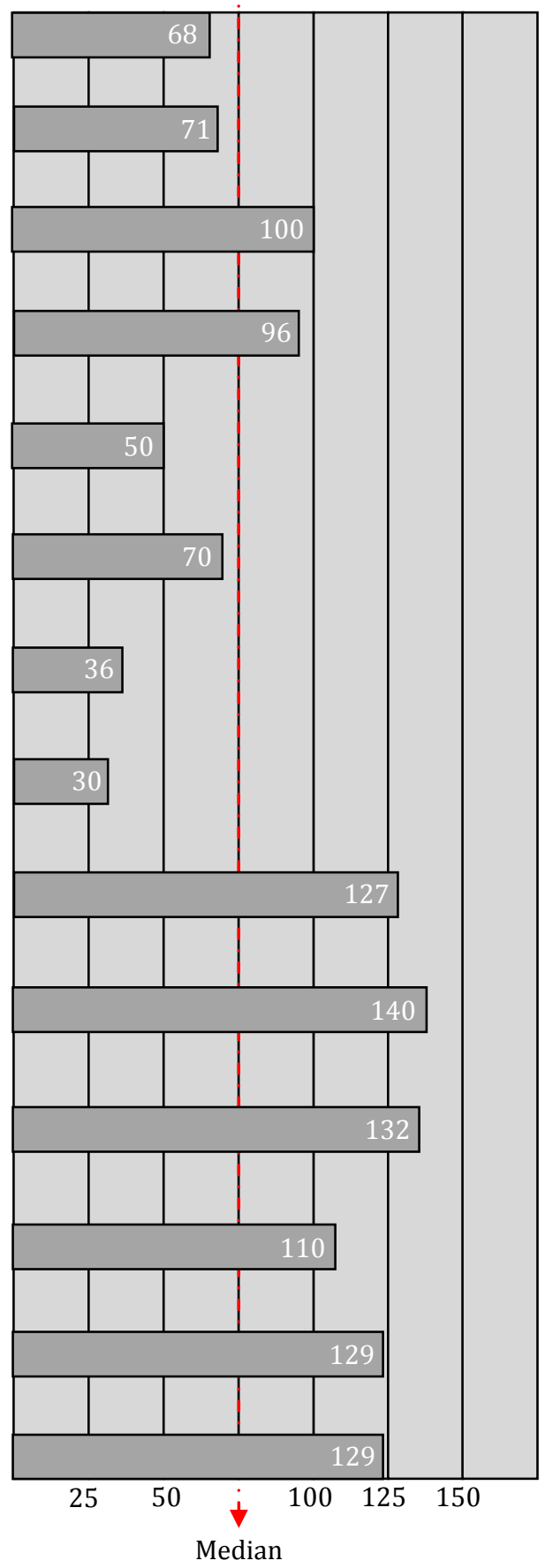

Fig. 4. Students' responses towards feedback practice via Kahoot assessment.

Fig. 4 showcase students' responses towards the feedback practice that they experience with Kahoot assessment. There's evidence of which Kahoot assessment covers four out of seven of the principles for good feedback practice. The first principle of which Kahoot assessment contribute the most would be that it encourages positive motivational beliefs and self-esteem. Following the chart, 140 students stated that Kahoot assessment increase their motivation to participate in the activity and 127 students stated that it also boost their self-esteem towards their performance in class. This reflect upon Kahoot assessment abilities to increase students' enthusiasm to take part in classroom assessment activities. As for the second principle, Kahoot assessment also contribute in assisting educators to shape their teaching skills. As 
evidence, there are 129 students who agrees that Kahoot assessment is a good practice for lecturer to run in classroom and it improves lecturer's capability to encourage students' participation in subject assessment. The third principle of which Kahoot assessment contribute to would be that it provide opportunities for students to close the gap between current and desired performance. This reflect upon the result to which 132 students agree that they are able to achieve desired scored from the test and 110 students agrees that Kahoot assessment actually assist them to perform well in the subject. In similarity to Figure 3 and Table 1, this showcase that Kahoot assessment can improve students' performance level in classroom. As for the fourth principle, Kahoot assessment also manage to facilitate the development of self-assessment in learning. As evidence from the chart in Figure 4, 100 students agree that Kahoot assessment allow them to access and assess their performance against other students' performances and 96 students agree that this encourages self-reflection towards how well they are doing in the subject. On the other hand, Kahoot assessment are lacking towards three principles and one of it would be students' difficulties to gauge the goal and criteria of the assessment. Only slight 71 number of students are aware of the expected standard in meeting the criteria of the test and 68 students are aware on what to achieve in the test. Secondly, Kahoot assessment also lacking in delivering high quality of learning information from the activity. Only 50 students manage to learn more information on post-test learning and only 70 students agree that the test improve their knowledge towards the subject. Thirdly, Kahoot assessment hardly encourage educator and peer dialogue during the activities. Only 36 students agree that they can discuss with lecturer in regards to the assessment and only 30 students stated that Kahoot assessment give them opportunity to have conversation in regards to the subject content.

Respondents clearly have positive responses towards the usage of technology application as an assessment tool in classroom, specifically for Kahoot assessment. From the findings, Kahoot assessment deemed as an interactive and engaging tool that encourages students' participation in classroom. In similarity, [2] stated that technology application in classroom lesson can be very effective towards gaining students' extra attention. Additionally, a study [5] describe the usage of technology can improve students' assessment and feedback practice in class. In parallel to the findings, students do believe that Kahoot assessment manage to encourage positive behavior towards assessing their level of understanding towards the subject. Given that they are exposed not only to their scores but also to other classmates' scores, it will give them the push to perform better among their peers. However, a study [3] did mentioned the issues and concerns towards technology application in classroom assessment towards students' good feedback practice. In addition to that, the findings also manage to discover several flaws in Kahoot assessment feedback practice where it discourage students' dialogue and conversation with lecturers during the test, the absolute objective of the test is not clear and that the test does not necessarily improve students' learning towards the subject. In addition, a study [4] stated that there still need to have much improvement with the current usage of technology application in classroom activities in presenting a full quality feedback practice among students and educators.

\section{Summary and Conclusion}

This study provide further knowledge and understanding towards the effectiveness of technology application as an assessment tool in classroom activities. The underlying factor is to study the usage of Kahoot assessment tool and its' effect towards students' performance level and feedback practice in classroom activities. Past study [9] discuss how seven principles of good feedback practice can result to a better learning quality for students and educators. Results present evidence towards how Kahoot assessment manage to improve students' performance however, in regards to the seven principles of good feedback practice, the assessment only manage to fulfill four out of seven principles. Additionally, a study 
[10] describe how one of the concern towards technology assessment is students' and educators' inability to gauge how the gaming and fun interactivity can capture the seriousness of assessment. Nevertheless, technology application tool for assessment in classroom were found to provide strong engagement among students that encourage their active participation in class. For the implication for future research, studies can be done towards finding out methods in making technology application assessment tool more focus towards students' dialogue with lecturers, clearer goals and objectives and improvement towards the delivery of information through the assessment.

\section{Acknowledgment}

This work was supported by a research grant from KDU University College (KDURG/2016/1/002).

\section{References}

[1] Poly, C., \& Obispo, S. L. (2007). The Role of Technology in Improving Student Learning of Statistics, 1(1).

[2] Brand, B. G. A. (1997). What Research Says: Training Teachers for Using Technology, 19(1).

[3] Bitner, N., \& Bitner, J. O. E. (2002). Integrating Technology into the Classroom: Eight Keys to Success, 10, 95-100.

[4] Helvoort, J. (2010). A scoring rubric for performance assessment of information literacy in Dutch higher education. Journal of Information Literacy, 4(1), 22-39.

[5] Cuban, L. Computers Meet Classroom: Classroom Wins.

[6] Greenhalgh, T. (2001). Computer assisted learning in undergraduate medical education. 322.

[7] Moersch, B. Y. C. (1998). Levels of Technology Implementation (LoTi ): A Framework for Measuring Classroom Technology Use.

[8] Saadé, R. G. (2003). Web-based educational information system for enhanced learning. EISEL: Student Assessment, 2.

[9] Nicol, D., \& Milligan, C. (2006). Rethinking technology-supported assessment practices in relation to the seven principles of good feedback practice. 1-14.

[10] Strommen, E. F. (1992). The Future of Classroom Learning, 24(4), 466-476.

[11] Pugh, K., Sheldon, S., \& Byers, J. O. E. L. (2002). Conditions for Classroom Technology Innovations, 104(3), 482-515.

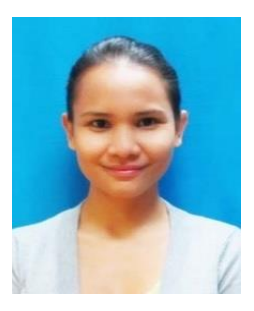

Nurul Nisa Omar is a Ph.D. holder from Multimedia University Malaysia who possess a passion for teaching and is a dedicated educator. She is very active in research activities and currently leading a research project under a local grant. Her first research achievement was for a paper on educational online games which she achieved the silver award at the International Conference on Advances in Computer Entertainment Technology. Additionally, she participated in other international research conferences which include Asian Conference on Arts and Humanities, European Conference on Media and Mass Communication, International Conference on Education and Management Technology and many others. 